\title{
PETER PINKERTON, M.A., D.Sc., LL.D., F.R.S.E.
}

\section{By John Dotgall.}

Bx the death of Dr Pinkerton on 22nd November 1930, at the comparatively early age of 60 , we lost a fellow member who in times past had given varied and valuable service to our Society, and who, as Rector of the High School of Glasgow, occupied a distinguished position among Scottish teachers.

Peter Pinkerton was born in Kilmarnock on 8th June, 1870. He received his early education in the Academy there, and was Medallist in Classics and Mathematics. In 1886 he entered Glasgow University. In 1890 he graduated M.A. with First-class Honours in Mathematics and Natural Philosophy, and was awarded the Breadalbane and John Clark Scholarships in those subjects. For two years thereafter he attended the Royal College of Science, Dublin. He took first places in Mathematics, Mechanics, Physics and Chemistry, and second place in Botany.

From 1st September, 1893 to 31st August, 1899, he was Mathematics Master in Allan Glen's School, Glasgow. From September, 1899, to December, 1902, he was Headmaster of the Mathematical Department of the Royal Academical Institution, Belfast. From January, 1903 to December, 1913, he was Head of the Mathematical Department in George Watson's College, Edinburgh ; and from October, 1911, he acted as deputy headmaster. From 1st January 1914, till his death, he was Rector of the High School of Glasgow.

Early in his career he became a Fellow of the Royal Society of Edinburgh. In 1909 Glasgow University conferred upon him the degree of Doctor of Science, and in 1930 that of Doctor of Laws. With his alma mater he always maintained a close connection. $\mathrm{He}$ was examiner for degrees on many occasions, and was an active member of committees of the General Council.

Dr Pinkerton was elected to the Edinburgh Mathematical Society in December 1893. He was Secretary from 1904 to 1908 inclusive, and President in 1908-9. He was Editor of Mathematical Noles from its first number, published in 1909, till 1913. 
He contributed many papers to the publications of the Society. Perhaps the best way to indicate their nature and scope is to quote the titles. The following were printed in the Proceedings :

1. Note on Inequality Theorem regarding the Lines joining Corresponding Vertices of two Equilateral or Directly Similar Triangles. (XXII, 27).

2. The Turning Values of a Cubic Function, and the Nature of the Roots of a Cubic Equation. (XXII, 86-89).

3. The Turning Values of Cubic and Quartic Functions, and the Nature of the Roots of Cubic and Quartic Equations. (XXIII, 43-48).

4. On a Nine Point Conic, etc. (XXIV, 31-33).

5. The Parabolic Path of a Projectile. (XXIV, 34).

6. Points at Infinity, etc., in a Plane. (XXV, 26-35).

7. On Area Theory and some Applications. (XXV, 69-79).

His contributions to Mathematical Notes were on :

1. Quadratic Equations. (No. 1, 10-12).

2. Similar Figures. (No. 3, 29-30).

3. Internal and External Bisectors, and an Example of Continuity. (No. 3, 30-32).

4. The Asymptotes of the Hyberbola. (No. 6, 63-65).

5. Rate of Change of Momentum. (No. 6, 66-71).

6. Deduction of Propositions on Tangents from Propositions on Secants. (No. 14, 164-167).

7. The Expansions of $\sin x$ and $\cos x$. (No. 14, 168-169).

8. Trigonometric Survey. (No. 17, 191-195).

The following papers were read before the Society but not published in the Proceedings:

1. Note on the problem : To draw through a given point a transversal to $(a)$ a given triangle, $(b)$ a given quadrilateral, so that the intercepted segments may have $(a)$ a given ratio, (b) a given cross-ratio. (1903-04).

2. The Scope of Elementary Geometry. (1910-11). 
His Thesis for the Doctorate of Science deals in a remarkably interesting way with the use of algebraic sign in elementary geometry. It brings out by means of a great variety of examples how the idea of sign-as applied, e.g. to segments, areas, radii of circles, common tangents to two circles-allows proofs to be stated in such a way that they will apply word for word to each and all of the diverse cases which may occur. The Thesis does not seem to have been printed, but there is a manuscript copy in Glasgow University Library.

In collaboration with the late Professor Gibson, with whom he was on terms of close friendship from his student days, Pinkerton wrote a text-book on "Elements of Analytical Geometry," the first edition of which was published in 1911. The distinctive feature of this work is the stress it lays on that interesting and valuable part of a student's training, curve tracing. The sections on this subject were expressly intended to serve as an introduction to Frost's classical treatise, and the method of successive approximations is systematically used.

It will be seen that Pinkerton's papers practically all bear directly on school work. But his interests were by no means limited to elementary, or even to scientific, subjects. He never dropped his habit of mathematical reading, and he was keenly interested in modern mathematical physics, in some of its branches at least. $\mathrm{He}$ also read widely in general literature, and he was a keen golfer.

But it was in his daily work as a schoolmaster that Pinkerton was at his best. His power in the class-room was extraordinary. His energy and vivacity were untiring. He seemed to be always at his highest level, and without apparent exertion he kept the boys at theirs. The key-word to Pinkerton's method was "thorough." In his teaching, as in his thought, he hated the slipshod. He disliked intensely the habit of confusing a proposition with its converse. He was fond of "reversible" proofs, and trained his boys to recognise reversibility when they saw it.

Professor D. K. Picken, who was one of his earliest pupils in Allan Glen's. remarks " that "Pinkerton's outstanding merit as a teacher was directly related to his powers of original thought. His mathematical thought was his own; he thought things through for

1 Glasgow High School Magazine, Dec. 1930. 
himself, and was master of his subject. He made contributions of real value to the matters in which he was specially interested. It is not sufficiently realised that divorce-even divorce of interestbetween teaching and research, is ultimately detrimental to both."

As the Rector of a great school, Pinkerton was a conspicuous success. His rule was rigorous, but just and sympathetic. His boys had to work hard, but they did it willingly. He knew every boy individually and intimately. To the boys themselves the accuracy and completeness of his knowledge of their personal histories and idiosyncrasies seemed almost uncanny. He was admired and loved, by boys and masters alike. The whole atmosphere of the school was permeated with a spirit of unbounded confidence in the Rector.

Dr Pinkerton had been a widower for many years. $\mathrm{He}$ is survived by one son, Dr Herbert Pinkerton. 